\title{
Novel approach for quantifying illegal bushmeat consumption reveals high consumption of protected species in Madagascar
}

\author{
Julie H. Razafimanahaka, Richard K. B. Jenkins, Daudet Andriafidison, \\ Félicien Randrianandrianina, Victor Rakotomboavonjy, Aidan Keane and \\ Julia P. G. JONES
}

\begin{abstract}
Information on the extent of bushmeat hunting is needed to assess the likely impact on hunted species, to provide information on the opportunity cost to local people of conservation, and to judge the efficacy of interventions at reducing pressure. However, where hunting is illegal, or socially unacceptable, respondents may not answer honestly to direct questions about hunting or consumption of bushmeat. We adapted a specialized method for investigating sensitive behaviours (the randomized response technique, RRT) and questioned 1,851 people in Madagascar about their consumption of six species, using either RRT or direct questions. For most species at most sites RRT and direct questions returned similar estimates of the proportion of the population who had consumed bushmeat in the previous year. However, RRT resulted in significantly higher estimates of bushmeat consumption in communities surrounding a protected area, where conservation activities made such questions sensitive. RRT has been predominately used in Europe and the USA; we demonstrate that it can provide a valuable approach for studying rule-breaking among people with poor literacy in low income countries. Between 12 and $33 \%$ of people across our sites had eaten brown lemur (Eulemur spp.), and $12-29 \%$ had eaten sifaka (Propithecus spp.) in the previous year. These results add to the growing body of evidence that hunting of protected species in Madagascar is a serious problem requiring urgent action. Conservation interventions to tackle bushmeat hunting will make questions about hunting or consumption more sensitive, increasing the need for researchers to use appropriate approaches for asking sensitive questions.
\end{abstract}

Julie H. Razafimanahaka, Richard K. B. Jenkins*, Daudet Andriafidison $\dagger$, FÉLICIEN RANDRIANANDRIANINA and ViCTOR RAKOTOMBOAVONJY Madagasikara Voakajy, Antananarivo, Madagascar

Aidan Keane $\ddagger$ and Julia P. G. Jones (Corresponding author) School of the Environment, Natural Resources and Geography, Bangor University, Bangor, Gwynedd, LL57 2UW, UK. E-mail julia.jones@bangor.ac.uk

*Also at: School of the Environment, Natural Resources and Geography, Bangor University, Bangor, Gwynedd, UK

†Also at: Département de Biologie Animale, Faculté de Sciences, Université d'Antananarivo, Antananarivo, Madagascar

‡Current address: Department of Anthropology, University College London, London, and Institute of Zoology, Regent's Park, London, UK

Received 8 December 2011. Revision requested 13 March 2012.

Accepted 3 April 2012.
Keywords Bushmeat, conservation effectiveness, enforcement, hunting, lemur, Madagascar, poaching, randomized response technique

\section{Introduction}

$\mathrm{B}$ ushmeat hunting is widely recognized as an important B threat to the biodiversity of tropical forests (MilnerGulland \& Bennett, 2003), causing extirpation of target species (Bouche et al., 2010) and cascading effects on ecosystems (Peres \& Palacios, 2007). Quantifying the extent of bushmeat hunting or consumption is important for several reasons, including quantifying the likely impact on hunted species (Fa \& Brown, 2009), understanding the role that it plays in local diets (Golden et al., 2011) and evaluating the success of interventions aimed at managing hunting (Mockrin \& Redford, 2011). The level of hunting in an area can be inferred from surveys of neighbouring bushmeat markets but identifying the provenance of meat is difficult (Allebone-Webb et al., 2011). Where hunting leaves visible signs, such as snares, these can be surveyed to indicate the extent of hunting in a specific area (Holmern et al., 2007) but this is very resource intensive. Interviews with local people can also be used to provide information about hunting or consumption (Ndibalema \& Songorwa, 2008). However, where hunting is illegal, because of legislation protecting particular species or within a protected area, those involved may not give honest responses for fear of punishment (Knapp et al., 2010; St John et al., 2010).

Social scientists have long recognized the challenges of gathering information from respondents about sensitive or illegal behaviours (Singer et al., 1995). By not collecting individually identifying information and guaranteeing confidentiality researchers encourage respondents to reveal involvement on sensitive behaviour. However, despite these efforts respondents may still be unwilling to reveal incriminating information (Lee, 1993). Methods, such as the Randomized Response Technique (RRT; Warner, 1965), have therefore been developed that protect the respondent further by making it impossible for their response to be tied to them as an individual. In RRT respondents use a randomizing device, such as a dice, to dictate whether they answer the sensitive question of interest, or a non-sensitive 
question. With a large sample it is therefore possible to estimate the proportion of respondents answering yes to the sensitive question but it is not possible to identify an individual's response, thus protecting the respondent (Warner, 1965). RRT has been widely used to investigate a range of sensitive behaviours, including fraud (Bockenholt \& van der Heijden, 2007), cheating in exams (Scheers \& Dayton, 1987) and illegal abortion (Silva \& Vieira, 2009). Its value has been recently recognized in environmental research (Gavin et al., 2010; St John et al., 2010, 2012). However, we know of only a single previous study (Solomon et al., 2007) that used RRT in a low-income country.

Madagascar is recognized globally as one of the hottest of the global biodiversity hotspots (Goodman \& Benstead, 2005). Although it is well known that wild meat forms part of the diet of rural people (Jenkins \& Racey, 2008; Randrianandrianina et al., 2010; Golden et al., 2011) and there has been concern about the sustainability of this hunting, particularly the pressure on more vulnerable species (Golden, 2009; Jenkins et al., 2011; Ravaloharimanitra et al., 2011), the issue of bushmeat hunting in Madagascar has received much less attention than such hunting in other biodiversity-rich tropical countries. This may be because the country lacks large urban markets for bushmeat (Jones et al., 2008) and thus the trade is not as obvious as in some countries ( $\mathrm{Fa}$ et al., 2000; Cowlishaw et al., 2005). Madagascar has an extensive system of wildlife legislation (Rakotoarivelo et al., 2011). Although the country's wildlife laws are poorly understood in general, it is relatively well known that lemurs are protected (Keane et al., 2011), which may make it difficult to investigate bushmeat hunting or consumption by asking direct questions.

We investigated consumption of six wild animal species in three regions of Madagascar (including areas surrounding a well-enforced protected area, and areas less exposed to conservation education or enforcement of conservation rules), using both RRT and direct questioning. Our objectives were to investigate whether RRT can improve estimates of the extent of bushmeat consumption, particularly for sensitive species or in sensitive sites, and investigate the extent of consumption of a selection of endemic Malagasy species.

\section{Methods}

\section{Species chosen}

Madagascar's wildlife laws classify species into three broad categories (Keane et al., 2011): protected species (which can't be killed or collected, or in some cases can be collected with a licence), game species (which can be hunted during a defined season for subsistence use as long as certain methods are avoided), and pest species (which can be killed at any time by anyone). Rakotoarivelo et al. (2011) provide more information on Madagascar's wildlife law and the sanctions in place. In each interview we included chicken, a domestic and widely-eaten species. Questions about chicken consumption would not be considered sensitive by the respondents and we expected no difference in estimated prevalence of chicken consumption between the two methods. We selected three game species (two categorized as Least Concern and one as Vulnerable on the IUCN Red List; IUCN, 2011) and three protected species (categorized as Endangered or Vulnerable; Table 1).

\section{Data collection}

Surveys were administered to a total of 1,851 villagers in six communes in three regions of Madagascar between November 2009 and June 2010 (Fig. 1). Two of these communes (Ambatovola and Andasibe in eastern Madagascar) border the Andasibe-Mantadia protected area complex (Mantadia National Park and the Analamazoatra Special Reserve), a long-established and relatively heavily-enforced protected area (Dolch, 2003) in the Alaotra-Mangoro Region, Moramanga District, in the east. Hunting of any wild species is forbidden within the park and staff patrol the forest and visit surrounding villages carrying out environmental education. Questions about hunting or consumption

TABLE 1 List of species included in the study, in western and eastern Madagascar (Fig. 1), their IUCN Red List category (IUCN, 2011) and legal status under Malagasy law.

\begin{tabular}{|c|c|c|c|}
\hline Common name & $\begin{array}{l}\text { Species used in the west } \\
\text { (Red List status)* }\end{array}$ & $\begin{array}{l}\text { Species used in the east } \\
\text { (Red List status)* }\end{array}$ & $\begin{array}{l}\text { Status under } \\
\text { Malagasy law }\end{array}$ \\
\hline Domestic chicken & Galllus gallus & G. gallus & \\
\hline Tenrec (terrestial insectivore) & Tenrec ecudatus (LC) & T. ecudatus (LC) & Game \\
\hline White-faced whistling duck & Dendrocygna viduata (LC) & D. viduata (LC) & Game \\
\hline Madagascan flying fox & Pteropus rufus (VU) & P. rufus (VU) & Game \\
\hline Brown lemur & Eulemur rufrifrons (NT) & Eulemur fulvus (NT) & Protected \\
\hline Fosa (large carnivore) & Cryptoprocta ferox (VU) & C. ferox (VU) & Protected \\
\hline Sifaka (large-bodied diurnal lemur) & Propithecus verreauxi (VU) & Propithecus diadema (EN) & Protected \\
\hline
\end{tabular}

*EN, Endangered; VU, Vulnerable; NT, Near Threatened; LC, Least Concern 

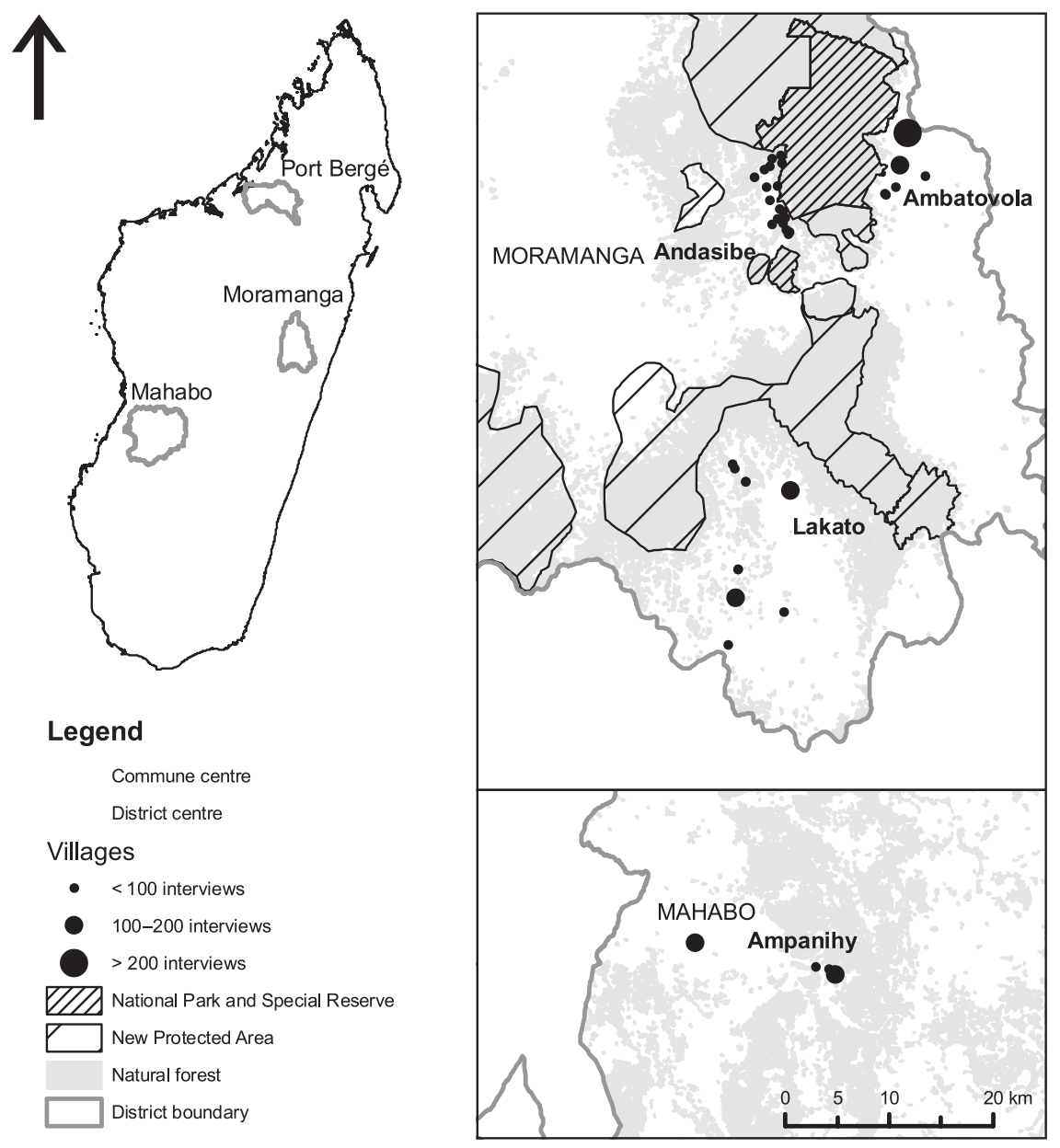

FIG. 1 Madagascar, showing the districts where we worked (Port Bergé, Mahabo and Moramanga), with panels showing Moramanga (includes both sensitive and non-sensitive eastern sites) and Mahabo (non-sensitive western site) in more detail.

of bushmeat are sensitive in these two communes, which we refer to as 'sensitive' eastern sites. We selected a third commune (Lakato) from the same district in eastern Madagascar, where such questions would be less sensitive because there has been little or no environmental education or enforcement of environmental legislation. At the time of our study the forest was in the process of being included in a protected area (a temporary protection order was granted by the government in 2010) but implementation had not yet begun. Lakato is therefore referred to as the 'non-sensitive' eastern site. The villages and households we selected were chosen to be as similar as possible between the two areas (with respect to variables such as access to the forest, species present in the area, livelihoods and ethnic background of local people). We also worked in two non-sensitive communes in the Menabe region (Mahabo and Ampanihy) and one in the Sofia Region, Port Bergé District (Tsiningia), in western Madagascar. Data collection was carried out by JHR, DA, FR and VR, all of whom are fluent in the local dialects of Malagasy. JPGJ and RKBJ, both fluent in conversational Malagasy, were involved in training, the pilot study and revising the survey instruments.

In all areas except Mahabo commune (a small town some distance from the forest), selected villages were within $5 \mathrm{~km}$ of natural forest. Sampling of households was ad hoc, with the research team visiting as many households as possible and asking whether they were willing to be interviewed. If villages had $>30$ houses we followed a zigzag pattern through the villages, visiting every 3 rd house (East et al., 2005). In smaller villages we visited all households where someone was home. We ensured we visited outlying houses and small hamlets as well as houses close to the centre of the villages. We explained the purpose of our study and that participation was voluntary, and there were a number of exit points during the interview at which we confirmed the respondents were happy to continue.

\section{Survey instruments}

The survey instruments were piloted in two villages in eastern Madagascar and refined and improved following discussion among the team. Respondents were randomly allocated one of the two survey instruments (direct questions or the RRT survey) by the researcher, who selected a coloured ball from a cloth bag (the number of each colour was manipulated to increase the sample of respondents answering with RRT) before entering the 
household to be interviewed. Pictures, previously tested locally to ensure they were easily recognized, of six wild species and chicken were shown to respondents.

In the survey with direct questions respondents were asked to respond simply 'have eaten' (efa nihinana) or 'haven't eaten' (mbola tsy nihinana) to the question about whether they had eaten each species in the last 12 months. In the randomized response technique survey we explained the method and said it was like a game (kilalao) and that like a game it has rules, which we asked the respondents to follow. We then worked through 2-4 example questions (using pictures of fish, bushpig, snake and cow) depending on how quickly they appeared to understand the method. Respondents were given a cloth bag containing 10 coloured balls. They were asked to select a ball and not show it to the interviewer. They were shown a picture of each species in turn and asked to answer the question 'have you eaten this species in the last 12 months?' If they had chosen a coloured ball (probability 8/10) respondents were asked to answer the question truthfully. Respondents were asked to simply say 'have eaten' if they selected a white ball $(P=1 / 10)$ and 'haven't eaten' if they selected a black ball $(P=1 / 10)$. Because the interviewer does not know whether a respondent is saying they have eaten a species because they have indeed eaten it, or because they selected a white ball, the interviewer does not have any definite information about the respondent. The probabilities associated with each response are given in Fig. 2.

\section{Analysis}

We tested for differences between our sample of respondents assigned to the RRT survey and the direct questions in terms of their age (with a $t$ test) and gender distribution (binomial proportion test). The proportion of rule-breakers in the RRT sample was estimated using the 'forced response' model (Hox \& Lensvelt-Mulders, 2004): $\pi=(\lambda-\theta) / P_{1}$, where $\pi$ is the estimated proportion of the sample who have broken the rule, $\lambda$ is the proportion of all responses that are 'have eaten', $\theta$ is the probability of being required to say 'have eaten', and $P_{1}$ is the probability of selecting the sensitive question. Ninety-five percent confidence intervals of the proportion of rule-breakers in each category were estimated from 1,000 bootstrap samples for the direct questions and RRT data, using $R$ v. 2.13.1 (R Core Development Team, 2010). Bootstrap sampling of the RRT data estimates uncertainty arising from the RRT method as well as sample uncertainty. We concluded that there was a significant difference between methods (or between two sites using the same methods) when the bootstrapped 95\% confidence intervals for the mean difference did not include zero (St John et al., 2010).

\section{Results}

Of the 1,851 interviews those conducted in Tsiningia (295) were discarded because of problems with the sampling and understanding of the method by the respondents (see Discussion). Therefore we present data from 1,557 interviews of which 1,137 were asked the questions using RRT and 420 were asked directly. In total, across all study sites, only 33 people refused to take part in the survey, giving a response rate of $98 \%$. All these made their decision before the interview method was selected. There was no difference between the samples allocated to RRT or direct questions in terms of age $(t=0.49, \mathrm{P}=0.626, \mathrm{DF}=703)$ or gender $(Z=0.10, \mathrm{P}=0.922)$.

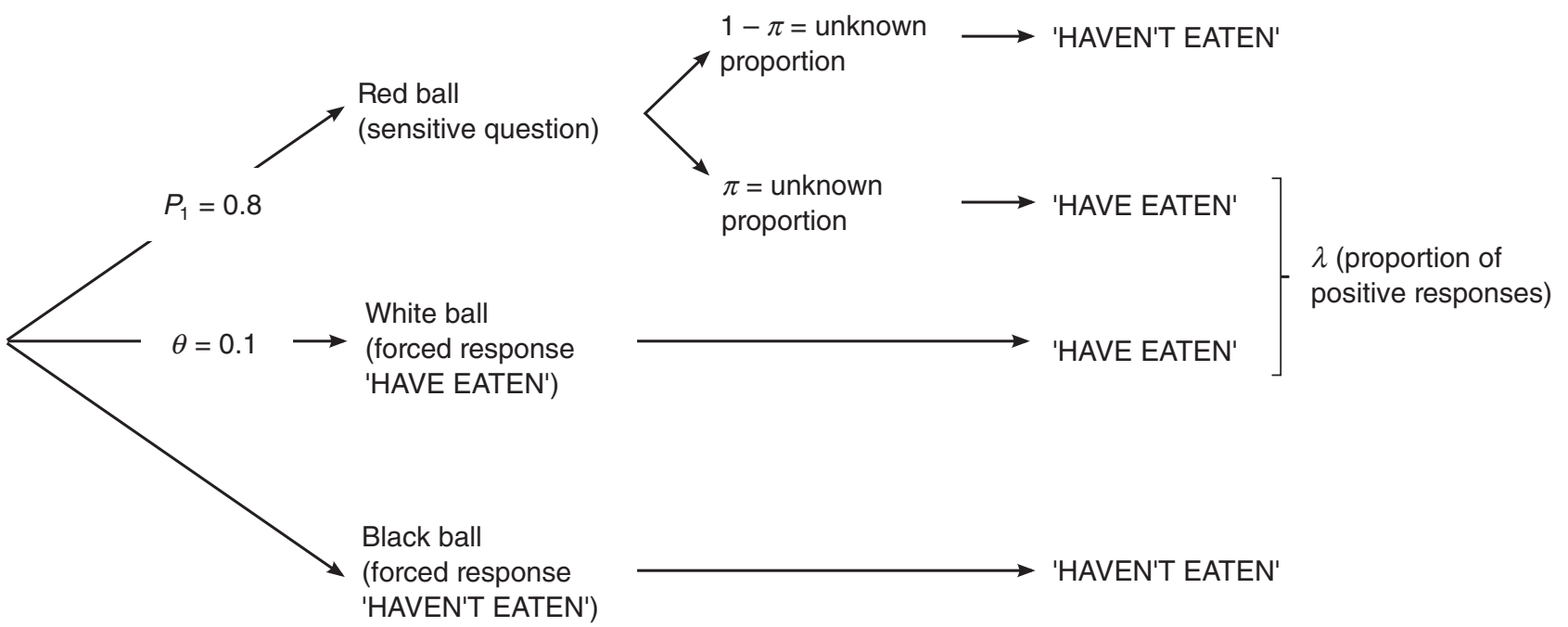

FIG. 2 Decision tree for a forced response RRT using eight red balls (where respondents are asked to answer the question honestly), one white ball (they are asked to say they have eaten the species) and one black ball (they are asked to say they haven't eaten the species). $\pi$ is the proportion of the sample who have broken the rule, $\lambda$ the proportion of all responses of 'have eaten', $\theta$ is the probability of being required to say 'have eaten', and $P_{1}$ is the probability of selecting the sensitive question. 


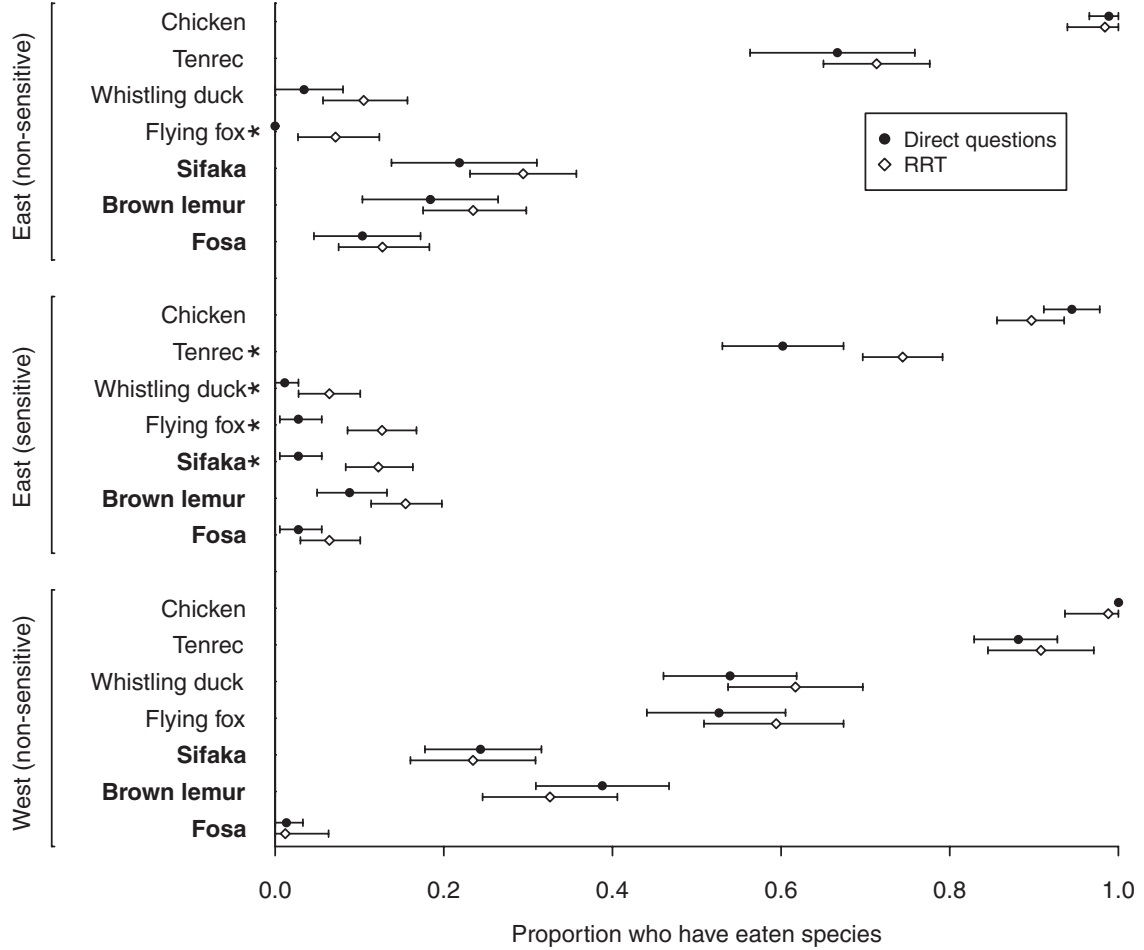

FIG. 3 Estimated proportion of respondents who had consumed each of seven species (Table 1) in the previous year in sensitive sites surrounding the protected area in eastern Madagascar (Andasibe and Ambatovola, $\mathrm{n}=761$ ), a non-sensitive commune in eastern Madagascar (Lakato, $\mathrm{n}=442$ ) and nonsensitive communes in western Madagascar (Mahabo and Ampanihy, $\mathrm{n}=371$ ). Points show the mean estimates from direct questions (filled circles) and RRT (open squares) and whiskers the 95\% confidence intervals derived from bootstrap resampling. Species in bold are protected under Malagasy law; * indicates that the estimates derived from the two methods differ significantly at the $5 \%$ level.

\section{Does RRT improve estimates of bushmeat consumption?}

We found no significant differences, using both methods, between the estimated proportions of the population who had eaten chicken in the last year, or in the proportion of people who had eaten the wild species in non-sensitive western sites, even for protected species such as lemurs (Fig. 3). In the non-sensitive eastern site the estimate from RRT was significantly higher than that derived from direct questions for Madagascar flying fox Pteropus rufus only, whereas in the sensitive sites (surrounding MantadiaAndasibe protected area) RRT returned higher estimates for all the wild species and this was significant for all species except fossa Cryptoprocta ferox and brown lemur Eulemur fulvus. For sifaka Propithecus diadema the estimate of the proportion of the population who had eaten the species was nearly four times higher using RRT than using direct questions (Fig. 3). To put this into context, using direct questions we would have concluded that only $3 \%$ of respondents had eaten sifaka in the previous year in the two communes surrounding Andasibe-Mantadia protected area; this increased to $12 \%$ using RRT.

\section{The extent of bushmeat consumption}

The estimated proportion of people who had consumed bushmeat in the previous year varied between species and between regions, whichever method was used. In all three study regions tenrec Tenrec ecudatus was the most widely consumed wild species investigated, with our estimates suggesting that $70-90 \%$ of people had eaten it in the previous year. Two other game species included in the study (white-faced whistling duck Dendrocygna viduata and Madagascar flying fox) were both highly consumed in the west (both species had been consumed by $60 \%$ of people in the previous year) but much less widely consumed in the east $(<12 \%)$. The results suggest that within our sampled population in the west of Madagascar lemurs are widely consumed, with $23 \%$ of people having consumed sifaka and $33 \%$ brown lemur in the previous year (Fig. 3). In the nonsensitive eastern site consumption of lemurs was similarly common ( $29 \%$ consumed sifaka and $23 \%$ brown lemur), whereas estimated wild meat consumption was lower in the sites surrounding Andasibe-Mantadia protected area (12\% for both sifaka and brown lemur).

\section{Discussion}

Does RRT improve estimates of bushmeat consumption?

RRT was developed specifically to investigate sensitive questions (Warner, 1965). In theory it should reduce both non-response bias (in which a non-random proportion of individuals refuse to take part in a survey; Lahaut et al., 2002) and social-desirability bias (in which respondents hide the truth to project a favourable image; King \& Bruner, 2000), therefore removing the downward bias on estimates of the prevalence of a sensitive behaviour. There are many studies where RRT returns significantly higher estimates of sensitive behaviours in comparison to conventional 
surveys such as direct questioning, and this has been widely interpreted as evidence of more honest reporting (Scheers \& Dayton, 1987; Solomon et al., 2007; Silva \& Vieira, 2009). In addition, in the few validation studies where the true status of each individual is known RRT returns more accurate responses compared to conventional survey instruments (Lensvelt-Mulders et al., 2005). Where questions are nonsensitive similar levels of reporting using direct questions and RRT are expected.

We found that both methods of questioning returned similar estimates of the proportion of respondents who have eaten a given species in many situations. In the nonsensitive sites in the west there was no difference between the estimates returned using the two methods and in the non-sensitive eastern site there was only a significant difference for one species (flying fox; an infrequently eaten meat in the area). Knowledge of wildlife laws among the general public in Madagascar is low (Keane et al., 2011) and we suggest that questions about bushmeat consumption, even of protected species, were not perceived as sensitive. In contrast, around the well-established Andasibe-Mantadia protected area (the eastern sensitive site) RRT returned higher estimates of the proportion of respondents who had consumed a species in the last year for all of the wild species and this difference was significant for most. We suggest that the higher levels of reporting of bushmeat consumption using RRT at this site reflect the fact that wildlife laws are relatively well known because of the long history of engagement by government, scientists, conservation NGOs and tourists (Dolch, 2003), and that people are therefore uncomfortable admitting, when asked directly, consumption of wild species.

In the only other study to use RRT to investigate illegal natural resource use in a low-income country (Solomon et al., 2007) found that estimates of various illegal behaviours, such as timber harvesting and bushmeat hunting within a national park were between 1.5 and 22 times higher when RRT was used compared to direct questions. The difference between estimates obtained using the two methods was lower in our study, where the largest difference was the estimate for sifaka consumption in the sensitive eastern site, which was four times higher using RRT compared to direct questions. The increase in reporting under RRT compared to direct questions is likely to depend both on how sensitive the questions are (with questions not perceived as particularly sensitive resulting in smaller differences between the two methods) and the degree to which RRT removes the sensitivity in the eyes of respondents.

\section{Challenges and limitations of using RRT}

For RRT to deliver a less biased estimate of the prevalence of a sensitive behaviour the respondents must understand the protection which the approach provides. The majority of studies that have used RRT are from the USA and Europe, and it is therefore useful for us to provide some detail about our implementation of the approach.

We trialled a number of different ways of explaining the approach during the pilot study and found that using the analogy of a game with rules worked well. We also found that training a well-known individual from each village and asking them to explain the method to respondents was beneficial. In each area members of our research team were fluent in the local dialect, meaning that problems with language could not be the cause of the improvement in comprehension when a local person explained the method. Instead we believe that seeing a familiar person who was clearly comfortable with this novel idea gave respondents the confidence to engage with the explanation and believe that they would understand it. We initially used a dice as the randomising device (as is done in most studies in highincome countries; e.g. Lensvelt-Mulder et al., 2005) but we abandoned this approach as the association between dice and divination (sikidy) across much of Madagascar made some respondents uncomfortable.

Despite our best efforts to describe the method some people found it confusing and difficult to understand. We had to discard the data from one site (Tsiningia) where our team felt that older and less educated people were having trouble understanding RRT and therefore they selected only younger and more educated respondents for the RRT questions, making comparisons between the methods invalid. Even where people understood the approach and the protection it offered, some, particularly older people, found it frustrating, and even rude, to be asked questions in such a convoluted way. Some also found it distressing to be asked to say they had eaten a species (by drawing a white ball from the bag) when that species was taboo ( fady) to them.

Although RRT may increase reporting of sensitive questions, it may not result in $100 \%$ honest reporting of sensitive behaviours even if respondents fully understand the protection offered by the method. This is because although RRT protects individuals the whole purpose is to reveal the behaviour of groups, and therefore where respondents are concerned about incriminating their group (e.g. their community, ethnic group or profession), RRT may not be effective. Solomon et al. (2007), in their study of resource use around a Uganda park, found that illegal behaviours were reported less frequently, using RRT, in a village that had suffered directly from enforcement of conservation rules than in a village where this had not occurred. They had no independent information on the frequency of the illegal behaviours. In such situations it is not possible to completely disentangle whether the enforcement has been effective at reducing the illegal behaviour or RRT hasn't fully removed the effect of 
question sensitivity and villages exposed to different regimes report a different percentage of these behaviours.

In conclusion, RRT has disadvantages over direct questions in terms of the complexity of the interview process, and the random noise added to the data, which means that larger samples are needed (St John et al., 2010). There is clearly no reason to use this approach to investigate a subject not perceived as sensitive by the respondents. Even where it may be advantageous to use the method in principal, if respondents are not comfortable with the method or do not understand it, RRT will not improve estimates of the prevalence of the behaviour of interest. However, we found that RRT provided much higher estimates of consumption of bushmeat species in an area where respondents were particularly aware of wildlife laws (making questions about bushmeat consumption highly sensitive). Based on theory, evidence from other studies, and our experience with using this method, we conclude that these higher estimates are more accurate and we suggest that RRT can be a valuable approach for investigating the prevalence of illegal or sensitive behaviours among rural communities in a low-income country.

\section{The extent of bushmeat consumption}

This study suggests that consumption of protected species such as lemurs is widespread among our sampled population. We estimate that for both lemur taxa included in the study $>10 \%$ of the sampled population have eaten them in all three study areas, and estimates were as high as $30 \%$ for some species and sites (brown lemur in the west and sifaka in the non-sensitive eastern site). It is not possible to extrapolate from our sample to the population of Madagascar as a whole because the sampling was far from representative. However, such high levels of consumption are clearly of concern. Primates tend to have relatively slow life histories, which makes them vulnerable to hunting (Peres, 2000; Fa \& Brown, 2009), most of the larger diurnal lemurs are thought to be affected by hunting (Mittermeier et al., 2011) and there is evidence that hunting may have played a part in the extinction of some Malagasy lemurs (Perez et al., 2005). This study adds to a growing number of reports (Garcia \& Goodman, 2003; Jenkins \& Racey, 2008; Barrett \& Ratsimbazafy, 2009; Golden, 2009; Randrianandrianina et al., 2010; Jenkins et al., 2011) suggesting that hunting and consumption of wild animals in Madagascar may be more widespread than previously thought, and deserves urgent attention from conservationists.

Although the tenrec was widely consumed in all three areas, consumption of the other two game species (the flying fox and the white-faced whistling duck) was much higher in the west (and in the west levels of consumption of tenrec reached 95\%). This finding of very high consumption of these game species in the west of Madagascar reflects the findings of other studies (Randrianandrianina et al., 2010) as well as our direct observations in the area and we believe it mostly reflects the relative abundance of these species in the west. Hunting of these game species has previously received little attention but research carried out as part of our project has demonstrated that despite the fast reproductive rate of tenrecs (Nicoll, 2003), their availability has declined over the last decade (Rajaonera, 2010).

How can bushmeat hunting in Madagascar be reduced?

Well-managed protected areas, where wildlife laws are enforced and local people share in the benefits of conservation (through ecotourism revenues or carbon payments), could provide refuges for heavily-hunted protected species. However, protected areas are not the only solution to unsustainable exploitation of bushmeat; the wider economic and institutional context within which hunting occurs must also be considered (Milner-Gulland \& Bennett, 2003). Many rural people in Madagascar are chronically undernourished (Dostie et al., 2002) and bushmeat can play an important role in reducing anaemia in Malagasy children (Golden et al., 2011). Evidence suggests, however, that bushmeat in Madagascar is considered inferior to domestic meats (Jenkins et al., 2011). Improving the supply of cheap domestic animal protein will be needed to reduce the pressure on wild animal populations within and outside protected areas while avoiding negative implications for human health. Other approaches include improved communication and enforcement of wildlife laws (Jenkins et al., 2011).

Reducing bushmeat hunting, particularly of threatened species, is a major challenge faced by governments and NGOs seeking to conserve biodiversity in the tropics. Unfortunately, even obtaining reliable information on the extent of hunting is challenging as those involved may not be willing to discuss it. The randomized response technique was developed to overcome some of the difficulties of interviewing people about their involvement in illegal or taboo behaviours and we suggest that it offers potential for investigating the extent to which wildlife protection, or other conservation rules, are broken. In this survey we found a relatively high proportion of our sampled population had eaten protected species, including threatened species such as the sifaka. The fact that consumption is so widespread is both evidence of the urgency of the issue and of how challenging it will be to tackle. Effectively reducing bushmeat hunting in Madagascar will require a multipronged approach involving improving the availability of alternative protein sources, education and enforcement. As people become more aware of the illegality of bushmeat 
hunting, approaches for asking sensitive questions will become increasingly important for collecting robust data.

\section{Acknowledgements}

We thank the Ministry of the Environment and Forests in Antananarivo, Moramanga, Morondava and Port Bergé for permission to conduct this work, and the Département des Eaux et Forêts at the Ecole Supérieure des Sciences Agronomiques and the Département de Biologie Animale, Faculté des Sciences (both in the University of Antananarivo) for their support and assistance throughout the project. We are also grateful to the personnel of Madagascar National Parks and mayors and village chiefs for permitting us to carry out this work. Gilbertoh Randrianantenaina and Robel Rajaonarison assisted with the interviews and Freya St John and two anonymous reviewers provided valuable comments. The work was funded by the UK Darwin Initiative (grant 17-1127) and Conservation International.

\section{References}

Allebone-Webb, S.M., Kumpel, N.F., Rist, J., Cowlishaw, G., Rowcliffe, J.M. \& Milner-Gulland, E.J. (2011) Use of market data to assess bushmeat hunting sustainability in Equatorial Guinea. Conservation Biology, 25, 597-606.

Barrett, M.A. \& Ratsimbazafy, J. (2009) Luxury bushmeat trade threatens lemur conservation. Nature, 461, 470-470.

Bockenholt, U. \& van der Heijden, P.G.M. (2007) Item randomized-response models for measuring noncompliance: riskreturn perceptions, social influences, and self-protective responses. Psychometrika, 72, 245-262.

Bouche, P., Renaud, P.C., Lejeune, P., Vermeulen, C., Froment, J.M., Bangara, A. et al. (2010) Has the final countdown to wildlife extinction in Northern Central African Republic begun? African Journal of Ecology, 48, 994-1003.

Cowlishaw, G., Mendelson, S. \& Rowcliffe, J.M. (2005) Evidence for post-depletion sustainability in a mature bushmeat market. Journal of Applied Ecology, 42, 460-468.

Dolch, R. (2003) Andasibe (Périnet): are conservation efforts sufficient to protect Madagascar's biodiervsity hotspot. In The Natural History of Madagascar (eds S.M. Goodman \& J.P. Benstead), pp. 1480-1485. The University of Chicago Press, Chicago, USA.

Dostie, B., Haggblade, S. \& Randriamamonjy, J. (2002) Seasonal poverty in Madagascar: magnitude and solutions. Food Policy, 27, 493-518.

East, T., Kumpel, N.F., Milner-Gulland, E.J. \& Rowcliffe, J.M. (2005) Determinants of urban bushmeat consumption in Rio Muni, Equatorial Guinea. Biological Conservation, 126, 206-215.

FA, J.E. \& Brown, D. (2009) Impacts of hunting on mammals in African tropical moist forests: a review and synthesis. Mammal Review, 39, 231-264.

Fa, J.E., Yuste, J.E.G. \& Castelo, R. (200o) Bushmeat markets on Bioko Island as a measure of hunting pressure. Conservation Biology, 14, 1602-1612.
Garcia, G. \& Goodman, S.M. (2003) Hunting of protected animals in the Parc National d'Ankarafantsika, north-western Madagascar. Oryx, 37, 115-118.

Gavin, M.C., Solomon, J.N. \& Blank, S.G. (2010) Measuring and monitoring illegal use of natural resources. Conservation Biology, 24, $89-100$.

Goodman, S.M. \& Benstead, J. P. (2005) Updated estimates of biotic diversity and endemism for Madagascar. Oryx, 39, 73-77.

Golden, C.D. (2009) Bushmeat hunting and use in the Makira Forest north-eastern Madagascar: a conservation and livelihoods issue. Oryx, 43, 386-392.

Golden, C.D., Fernald, L.C.H., Brashares, J.S., Rasolofoniaina, B.J.R. \& Kremen, C. (2011) Benefits of wildlife consumption to child nutrition in a biodiversity hotspot. Proceedings of the National Academy of Sciences of the USA, 108, 19653-19656.

Holmern, T., Muya, J. \& Roskaft, E. (2007) Local law enforcement and illegal bushmeat hunting outside the Serengeti National Park, Tanzania. Environmental Conservation, 34, 55-63.

Hox, J.J. \& Lensvelt-Mulders, G. (2004) Randomized response analysis in Mplus. Structural Equation Modeling: A Multidisciplinary Journal, 11, 615-620.

IUCN (2011) IUCN Red List of Threatened Species v. 2011.1. Http://www.iucnredlist.org [accessed 11 February 2011].

Jenkins, R.K.B., Keane, A., Rakotoarivelo, A.R., Rakotomboavonjy, V., Randrianandrianina, F.H., RaZafimanahaka, H.J. et al. (2011) Analysis of patterns of bushmeat consumption reveals extensive exploitation of protected species in eastern Madagascar. PLoS ONE, 6, e27570.

Jenkins, R.K.B. \& RaceY, P.A. (2008) Bats as bushmeat in Madagascar. Madagascar Conservation \& Development, 3, 22-30.

Jones, J.P.G., Andriamarovololona, M.A. \& Hockley, N.J. (2008) The role of taboos and social norms in conservation in Madagascar. Conservation Biology, 22, 976-986.

Keane, A.M., Andriamatsiaro, R.A., Jones, J.P.G. \& MilnerGulland, E. (2011) Evidence for the effects of education and environmental engagement on knowledge of wildlife laws in Madagascar. Conservation Letters, 4, 55-63.

KING, M.F. \& BRUNER, G.C. (2000) Social desirability bias: a neglected aspect of validity testing. Psychology \& Marketing, 17, 79-103.

Knapp, E.J., Rentsch, D., Schmitt, J., Lewis, C. \& Polasky, S. (2010) A tale of three villages: choosing an effective method for assessing poaching levels in western Serengeti, Tanzania. Oryx, $44,178-184$.

Lahaut, V., Jansen, H.A.M., van de Mheen, D. \& Garretsen, H.F.L. (2002) Non-response bias in a sample survey on alcohol consumption. Alcohol \& Alcoholism, 37, 256-260.

LeE, R.M. (1993) Doing Research on Sensitive Topics. SAGE Publications, London, UK.

Lensvelt-Mulders, G., Hox, J.J., van der Heuden, P.G.M. \& MAAs, C.J.M. (2005) Meta-analysis of randomized response research: thirty-five years of validation. Sociological Methods \& Research, 33, 319-348.

Milner-Gulland, E.J. \& Bennett, E.L. (2003) Wild meat: the bigger picture. Trends in Ecology \& Evolution, 18, 351-357.

Mittermeier, R., Louis, E., Richardson, M., Schwitzer, C., LangRand, O., RYlands, A. et al. (2011) Lemurs of Madagascar. Conservation International, Washington, DC, USA.

Mockrin, M.H. \& Redford, K.H. (2011) Potential for spatial management of hunted mammal populations in tropical forests. Conservation Letters, 4, 255-263.

Ndibalema, V.G. \& Songorwa, A.N. (2008) Illegal meat hunting in Serengeti: dynamics in consumption and preferences. African Journal of Ecology, 46, 311-319. 
Nicoll, M.E. (2003) Tenrec ecudatus, Tenrec. In The Natural History of Madagascar (eds S.M. Goodman \& J.P. Benstead), pp. 1283-1287. The University of Chicago Press, Chicago, USA.

Peres, C.A. (2000) Effects of subsistence hunting on vertebrate community structure in Amazonian forests. Conservation Biology, $14,240-253$

Peres, C.A. \& Palacios, E. (2007) Basin-wide effects of game harvest on vertebrate population densities in Amazonian forests: implications for animal-mediated seed dispersal. Biotropica, 39, 304-315.

Perez, V.R., Godfrey, L.R., Nowak-Kemp, M., Burney, D.A., Ratsimbazafy, J. \& VASey, N. (2005) Evidence of early butchery of giant lemurs in Madagascar. Journal of Human Evolution, 49, 722-742.

R Core Development Team (2010) R: A Language and Environment for Statistical Computing. R Foundation for Statistical Computing, Vienna, Austria.

Rajaonera, M.L. (2010) Disponibilité et consommation de Tenrec ecaudatus dans le Fokontany de Manamby Commune d'Ampanihy, District de Mahabo, Région Menabe. Mémoire de fin d'études pour l'obtention du Diplôme d'Etudes Approfondies. Département des Eaux et Forêts, Ecole Supérieure des Sciences Agronomiques. Antananarivo, Madagascar.

Rakotoarivelo, A.R., Razafimanahaka, J.H., Rabesihanaka, S., Jones, J.P.G. \& JENKIns, R.K.B. (2011) Lois et règlements sur la faune sauvage à Madagascar: Progrès accomplis et besoins du futur. Madagascar Conservation \& Development, 6, 37-44.

Randrianandrianina, F.H., Racey, P.A. \& Jenkins, R.K.B. (2010) Hunting and consumption of mammals and birds by people in urban areas of western Madagascar. Oryx, 44, 411-415.

Ravaloharimanitra, M., Ratolojanahary, T., Rafalimandimby, J., Rajaonson, A., Rakotonirina, L., Rasolofoharivelo, T. et al. (2011) Gathering local knowledge in Madagascar results in a major increase in the known range and number of sites for Critically Endangered Greater Bamboo Lemurs (Prolemur simus). International Journal of Primatology, $32,776-792$.

Scheers, N.J. \& Dayton, C.M. (1987) Improved estimation of academic cheating behaviour using the Randomized Response Technique. Research in Higher Education, 26, 61-69.
Silva, R.D.E. \& Vieira, E.M. (2009) Frequency and characteristics of induced abortion among married and single women in São Paulo, Brazil. Cadernos de Saude Publica, 25, 179-187.

Singer, E., Vonthurn, D.R. \& Miller, E.R. (1995) Confidentiality assurances and response: a quantitative review of the experimental literature. Public Opinion Quarterly, 59, 66-77.

Solomon, J., Jacobson, S.K., Wald, K.D. \& Human, M.G. (2007) Estimating illegal resource use at a Ugandan park with the randomized response technique. Human Dimensions of Wildlife, $12,75-88$.

St John, F.A.V., Edwards-Jones, G., Keane, A., Jones, L., YARNELL, R.W. \& JONES, J.P.G. (2012) Identifying indicators of illegal behaviour: carnivore killing in human-managed landscapes. Proceedings of the Royal Society B, 279, 804-812.

St John, F.A.V., Gibbons, J.M., Edwards-Jones, G. \& Jones, J.P.G. (2010) Testing novel methods for assessing rule breaking in conservation. Biological Conservation, 143, 1025-1030.

WARNER, S.L. (1965) Randomized response: a survey technique for eliminating evasive answer bias. Journal of the American Statistical Association, 60, 63-69.

\section{Biographical sketches}

Julie Razafimanahaka joined Madagasikara Voakajy (MV) as a student and is now Director. She is passionate about finding ways to fully involve communities in conservation. RICHARD JENKINS tackles the use and abuse of biodiversity (e.g. bushmeat hunting, mining and trade). $\mathrm{He}$ is involved in creating new rainforest protected areas in Madagascar. DAUDET ANDRIAfidison is studying the ecology and conservation of fruit bats while leading the community and conservation programme of MV. FÉLICIEN RANDRIANANDRIANINA started working with MV as a student in 2004 and led MV's first bushmeat work. Victor RAкотомвоAVONJY is from the Moramanga region, where he carried out many interviews for this study. AIDAN KEANE applies statistical and modelling techniques to interrogate data about interactions between people and their environment. JULIA JONES is particularly interested in applying approaches and methods from the social sciences to natural resource management issues. 